\title{
THE CHEMICAL RECYCLE OF COTTON
}

\author{
A.B. Schuch ${ }^{1 *}$ \\ 1 ESMOD Berlin International University of Art for Fashion - Master Programme Sustainability in Fashion, \\ Berlin - Germany \\ *alice@beyer-schuch.com
}

Artigo submetido em 22/06/2016 e aceito em 20/08/2016

\begin{abstract}
The chemical recycle of cotton textiles and/or other cellulosic materials for the purpose of manufacturing regenerated high quality textiles fibres is a novel process. The objective of related research is based on the forecast of population growth, on resource scarcity predictions, and on the negative environmental impact of the textile industry. These facts lead the need of broadening the scope for long-term textile-to-textile recycle - as the mechanical recycle of natural fibres serve for limited number of cycles, still depends on input of virgin material, and offer a reduced-in-quality output. Critical
\end{abstract}

analysis of scientific papers, relevant related reports, and personal interviews were the base of this study, which shows viable results in laboratorial scale of using lowquality cellulosic materials as input for the development of high-quality regenerated textile fibres though ecological chemical process. Nevertheless, to scale up and implement this innovative recycle method, other peripheral structures are requested, such as recover schemes or appropriate sort, for instance. Further researches should also be considered in regards to colours and impurities.

KEYWORDS: chemical recycle of cellulose, regenerated fibres, high-quality textiles

\section{A RECICLAGEM QUÍMICA DE ALGODÃO}

\section{RESUMO}

A reciclagem química de tecidos de algodão e/ou outros materiais de celulose para a manufatura de fibras têxteis regeneradas de alta qualidade é um processo desenvolvido recentemente. O objetivo de pesquisar-se sobre o tema está baseado na previsão de crescimento populacional, na estimativa de escassez de recursos e nos impactos ambientais negativos relacionados aos processos da indústria têxtil. Esses fatores levam à necessidade de ampliação do escopo de reciclagem de têxtil-para-têxtil a longo prazo - visto que a reciclagem mecânica tem ciclos limitados, depende de acréscimo constante de matéria-prima virgem e ainda resulta em material de qualidade inferior. Analises críticas de publicações cientificas, leitura de relatórios relevantes, e entrevistas pessoais serviram como base informativa a esse texto, que apresenta resultados viáveis desenvolvidos em laboratório do uso de materiais de celulose de baixa qualidade como matéria-prima inicial para o desenvolvimento de fibras têxteis regeneradas de alta qualidade, através de processo químico ambientalmente favorável. Não obstante, para a ampliação e implementação desse método de reciclagem inovador, outras estruturas periféricas são necessárias, como por exemplo, recolhimento e separação apropriada de têxteis. Pesquisas futuras ainda devem ser consideradas com relação a cores e outras impurezas.

PALAVRAS-CHAVE: reciclagem química de celulose, fibras regeneradas, têxteis de alta qualidade 


\section{INTRODUCTION}

Textiles have had great importance to humankind throughout history, and remain so to these days. Unfortunately, the current fashion industry situation and its negative environmental and social impacts are no long justifiable. It is time to establish a pathway towards the elimination of poisons, toxins and discards, and create a sequence of actions to energize the fashion industry, stimulate innovation, foster social development, and restore environmental health.

This article focuses on environmental material development, in response to the negative impact of the current textile industry production practices. Considering the forecast of growth of population, rapidly decreasing resources (Ellen McArthur, 2013, pg.15) and the possibility of extending the life-cycles of natural fibres, such as cotton - thus reducing landfill, water consumption, and the direct dependence on arable land - an innovative recycle process is presented. It allows the continuous chemical recycling of cellulosic-based textiles without downcycle. This way, the concept of waste could be eliminated - redirecting pre or post-consumer clothes in a responsible business structure, closing gradually the loop towards circular economy concepts.

Polyester fibres represent the highest annual production volume in the textileindustry. Cotton - a natural cellulosic fibre - follows it with 26,000,000 tons produced per year, which uses $2.4 \%$ of the world's arable land. The negative environmental impact of conventional cotton production can be connected with the widespread use of agrochemicals. Fertilisers, insecticides, herbicides, growth regulators and defoliants have become an integral part of cotton production practices, consuming $11 \%$ of the world's agrochemicals. The use of pesticides is considered to be the most serious problem. Large quantities of the most toxic pesticides are used in the production of cotton, accounting for about $24 \%$ of the global consumption. The production of any crop in these conditions, including textile crops, results in some environmental degradation that can impact negatively on people's quality of live and diminish biodiversity through soil erosion. Water consumption is other subject of serious concern. In general terms, for growing and processing one kilogram of cotton, it is suggested that almost 10,000 litres of water are required, and additional quantities for dyeing vary drastically between 30 and 200 litres of water per kilogram (SEI, 2005).

Furthermore, population forecasts are predicting a global increase to nine billion people by 2050. By 2030 alone the additional three billion middle class consumers would require a further 175 to 220 million hectares of cropland to meet food and fuel demands, and not only that. Water usage would increase in more than $40 \%$ until the same date (McKinsey, 2011, pg.47-51). Consequently, by 2030, demand for agricultural products as its price is expected to rise 40 to $50 \%$ above 2010 levels (Ellen McArthur, 2013, pg.15). And an additional demand of 15 million tons of cellulosic fibres by 2030 is forecasted (Lauri, 2014). Besides that, the amount of waste globally is also expected to increase not only as a function of population growth but also as incomes rise in emerging markets and the world's new consumers adopt the trend towards 'disposable clothing' or 'fast fashion' (Ellen McArthur, 2013, pg.53).

Resource constraints present significant challenges to businesses in the clothing sector, but also present opportunities for businesses to extend the life of clothes and develop business models based around product re-use (WRAP, 2013, pg.11). In this context, the merits of a recycling approach to textile production become apparent. The possibility of chemically recycling natural fibres is a complemental alternative towards betterments on the whole fashion industry, which does not exclude another options such as mechanical recycle or synthetic chemical recycle. A comprehensive applicability of it also depends on external structures and still requires further research despite more complex issues such as dying or impurities. 


\section{MATERIALS AND METHODS}

This text is part of the sustainable textile research in chemical recycle of cotton realized for the Master Thesis in Sustainability in Fashion "Further - textile rebirth catalyst", a more comprehensive study which also draws upon design strategies, business models and consumer behaviour. For this research, critical analysis of papers and relevant reports, and personal interviews with the narrow number of developers on this theme were the main source of information.

\section{RESULTS AND DISCUSSIONS}

\subsection{Regenerated fibres as future textile alternative}

Regenerated, or man-made artificial fibres, are those in which a natural and renewable resource, such as cellulose, is manipulated - dissolved or chemically modified into a thermoplastic that can be melted - in order to allow filament production thought spinneret process. Some of known regenerated fibres are viscose and lyocell, made of cellulose from wood pulp.

In 2013 the annual production of textile industry reached 92.3 million tons (an average consumption of 12.7 kilograms per capita). From that, 32 million tons are natural fibres, with stagnated production since 2004 with variation in more or less 1.5 million, in which cotton represents around $80 \%$. The other 60.3 million tons are man-made fibres, synthetic and artificial, in which viscose represents 3.8 million tons and its ecological alternative NMMO-based solvent lyocell, known Tencel ${ }^{\circledR}$ from Lenzing AG, representing only 150,000 tons of it - with production capacity of 220,000 tons per year (Sixta et al., 2015) (Outi Les Pyy, 2014) (Lenzing, 2013).

New developments which offer a sustainable alternative for man-made cellulosic fibres productions are underway, considering estimation growth of man-made cellulosic fibres in average of 9.1\% per year until 2020 (Hummel, 2015), and ignited by the rediscovery of ionic liquids (Figure 1) as powerful cellulose solvents in 2002. In 1934, Graenacher registered the first use of organic salt to direct dissolution of cellulose. Although it has not reached the commercial market yet, ionic liquids claim to enable the production of many regenerated cellulose materials, including textiles and films (Olsson, 2014).

\footnotetext{
"...initial results demonstrate that cellulose can be dissolved without activation or pretreatment in, and regenerated from, 1-butyl-3methylimidazolium chloride and other hydrophilic ionic liquids. This may enable the application of ionic liquids as alternatives to environmentally undesirable solvents currently used for dissolution of this important bioresource." (Swatloski et al., 2002)
}

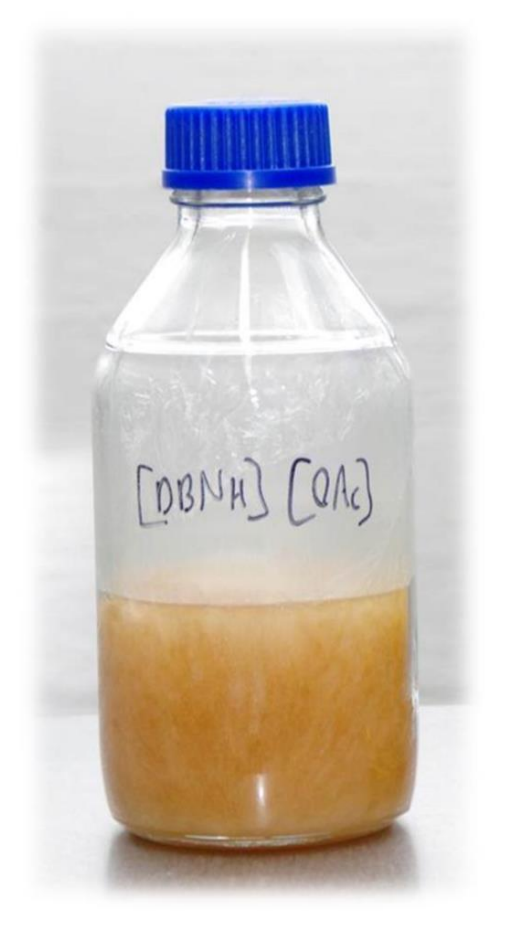

Figure 1: Sample of the Ionic Liquid 1,5-diazabicyclo[4.3.0]non-5enium acetate [DBNH]OAc at room temperature. Source: Ioncell-F

Ionic Liquids (ILs) are organic salts in liquid state with low melting point, usually less than $100^{\circ} \mathrm{C}$. They contain an organic caution/anion, have a very low vapour pressure even up to $300^{\circ} \mathrm{C}$, presents chemical and thermal stability, and are non-flammable (one difference from NMMO solvent from Tencel®). ILs are less aggressive to the environment, and are considered to be a green 
alternative to substitute organic solvents (Camacho, 2015). The extension of the Lyocell spinning technology to direct cellulose solvents of high thermal and chemical stability comprising lower solution viscosity is very attractive from a safety, environmental and economic point of view (Sixta et al., 2015).

In 2013, a group of Finnish scientists developed a new cellulose regeneration process in response to market growth and higher demand for sustainable textile production practices.

The project, led by Professor Ilkka Kilpeläinen and co-supervised by Dr A. W. T. King from Helsinki University has been conducted in collaboration with Professor Herbert Sixta's group at Aalto University, Department of Forest Products Technology. Kilpeläinen, King, and other researchers at the University of Helsinki have been responsible for the technological development of the recyclable ionic liquid, whereas, Aalto has concentrated on the spinning of the fibre and the textile production.

The ecological lyocell technology is completely covered by Lenzing AG and the company's policy prevents its license by other companies. However, in China (Shanghai Shuanglu Chemical Fiber Co.) and South Korea (e.g. Hanil, Hyosung) own NMMO-based lyocell fibre processes has been developed, with no commercial relevance yet (Outi Les Pyy, 2014).

Ioncell-F is a novel cellulose spinning process which uses non-toxic IL solvent. The complete dissolution of the pulp accomplished in less than 60 minutes and at much lower temperatures $\left(70^{\circ} \mathrm{C}\right.$ compared to $110^{\circ} \mathrm{C}-120^{\circ} \mathrm{C}$ for lyocell), what revels energy optimization. The process has shown great spinnability and mechanical characteristics, resulting in outstanding fibre properties from birch pulp. The new strength characteristics of the fibre has higher index than other regenerated fibres from the market. Initially, different tests were done, from 1 dtex $(\mathrm{g} / 10 \mathrm{~km})$ to higher - in a spinneret with 36 holes by 100 micrometre diameter each. The process was then optimized and a filament (Figure 2) was made of a constant dtex (1.2 or 1.5dtex). The titre of $1.2 \mathrm{dtex}$ is comparable to those already commercialised, and the fibre could be knitted or woven as other regenerated cellulose fibres. Elongation tests shown that the fibres are more resistant to deformation, which represents an advantage over Tencel® for example, avoiding the appearance of "knees" or "hanging-shoulders" on the fabric.

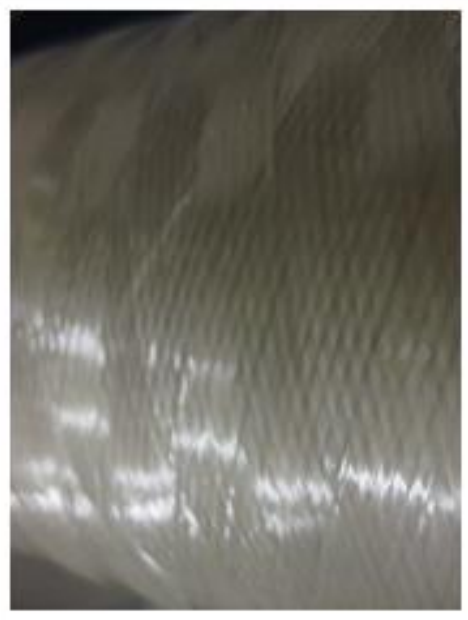

Figure 2: Bobbin of Ioncell-F filament at the end of spinning process.

Source: Schuch, AB (2015) from Aalto visit

No after treatment or finishing were applied during this initial laboratorial phase, though the post-spinning processes would follow the commercial ones (lyocell) considering dyeing, finishing, softeners, or brushes and could give even a higher quality to the produced fibres. Yarns and fabrics 
embrace a huge range of possibilities related to its construction: from filament to staple fibres, from light and transparent chiffons to heavy twill fabrics, from knitted to woven. Although different filament sections and shapes are not yet tested, it could also be considered as alternative for any different desired property.

\subsection{Ionic Liquids for the chemical recycle of cellulosic materials into regenerated textile fibres}

The chemical recycling of synthetic materials is not a new theme in the textile industry, but the field of natural-fibre chemical recycling is still in development. Back in 2011 (Fletcher \& Grose 2011:70), the chemical recycle was mentioned to be suitable only for synthetics. Five years later, it is shown to be possible and may present a great alternative in the extension of lifecycle of these fibres in the future. Company Patagonia recycles PET plastic bottles into PES fleece since 1993, and since 2005, closed the loop in garment-to-garment PES recycle in partnership with Teijin Group (Patagonia, 2009).

An ongoing study (Asaadi et al., 2014) analysed in 2015 (Ioncell-F, 2015a) may give deeper information about the chemical recyclability of cotton textiles. It is based on the previously described Ioncell-F process, with the use of the non-toxic ionic liquid DBNHOAc without cosolvents or stabilizers, in dry-jet wet spinning process, in cold-water coagulation bath. The research was developed using 100\% cotton textiles from used hospital bed sheets with different wood-pulps as input, what facilitates the analyses, without deviating the attention for other issues related to colours for example. The polymer concentration is also important, increasing the dope concentration results in fibre with higher tenacities. For Ioncell-F, the optimized polymer concentration is $13 \mathrm{wt} \%$.

For the success of the process, it is necessary to verify previously the viscosity of the cellulose before dissolution, despite the selected raw material. The adjustment of the DP (Degree of Polymerization - the length of the cellulose polymer chain) is the only pre-treatment that is needed. Natural wood has DP around 10000, wood pulp can vary between 300 and 1700, natural cotton has around 800, and regenerated fibres from cellulose usually have DP from 200 to 500 (Olsson, 2014). So for the spinning process, if the viscosity is too low, other material with higher viscosity should be added to guaranty the spinnability. In case of high viscosity, chemical processes could be applied in order to lower the viscosity level. Acid cooking could be an option, but a more environmental alternative could be an enzymatic hydrolyses.

In this way, any other cellulose based textile - like less-thirty crops such as linen or hemp or compounds - like wood buttons - could theoretically also be used as input. Even further, another research considered the use of paper in the production of new textiles fibres allowing the use of hand tags or packages in the same regenerated process (Ma, 2016).

For the use of paper, impurities as inks and glues should be rejected. For the related de-ink process, the company VTT informed to wash the pulp in water that contains certain amount of environmentally friendly/non-toxic dispersant (non-disclosure) (Ioncell-F, 2015a).

This study shows the possibility of using lignin - a by-product of the paper industry - in the spinning dope up to $50 \mathrm{wt} \%$. The input could be waste cardboards, giving a natural range of brownish colour (Figure 3). But observations must be considered when using lignin, because in high concentrations generate a weaker filament, although it can be still appropriate to certain textile requirements and performance. 


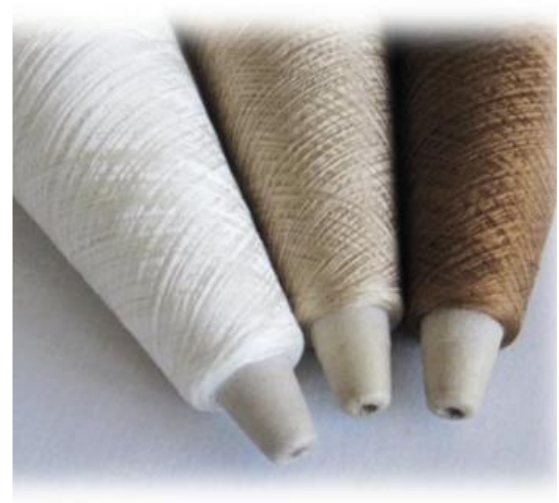

Figure 3: Different shades of produced yarn with or without lignin containing spun Ioncell-fibres.

Source: Ioncell-F

Important to mention, there are differences between cellulose I from natural sources and cellulose II from regenerated processes. The structure of the molecule and its hydrogen connections suffer a change when processed. Those regenerated cellulose are at the lowest level of DP necessary for spinning (from 350 to 550 for Ioncell-F and around 250 for NMMO). So, would be unlikely the use of $100 \%$ recycled cotton (in this terms) as unique raw material for the re-regenerating process. This means that an additional source with higher chain connections would be needed to equalize the ideal range of viscosity for spinnability. In this sense, wood pulp, used paper or other textile pulp with higher DP may be added at basically every re-process. Natural cotton, as mentioned, has DP around 800, which is too high for IL process thus it should be pre-treated before the dissolution. Nevertheless, cotton textiles suffer with the use and the home-washing processes (most of them are alkali detergents, reducing the DP length of cellulose polymer chain).

A sample from a sheet that had been laundered more than 50 times can reach the DP range of what is preferred by viscose producers (Palme at al., 2014). With these parameters, it is possible to spin a regenerated fibre from pre- and post-consumer waste, mixing regenerated and natural fibre, or from $100 \%$ cotton textile (Graphic 1). And in the laboratorial results, $100 \%$ reused cellulose fibres from Ioncell-F have shown higher tenacity and lower elongation index than commercial regenerated cellulose fibres. The research shown that $100 \%$ waste cotton is spinnable when final viscosity is adjusted. Although, a better tenacity and high orientation is shown when blended with wood pulp because allows higher draw-ratios, resulting in a thinner but stronger filament (Graphic 2 and Graphic 3).

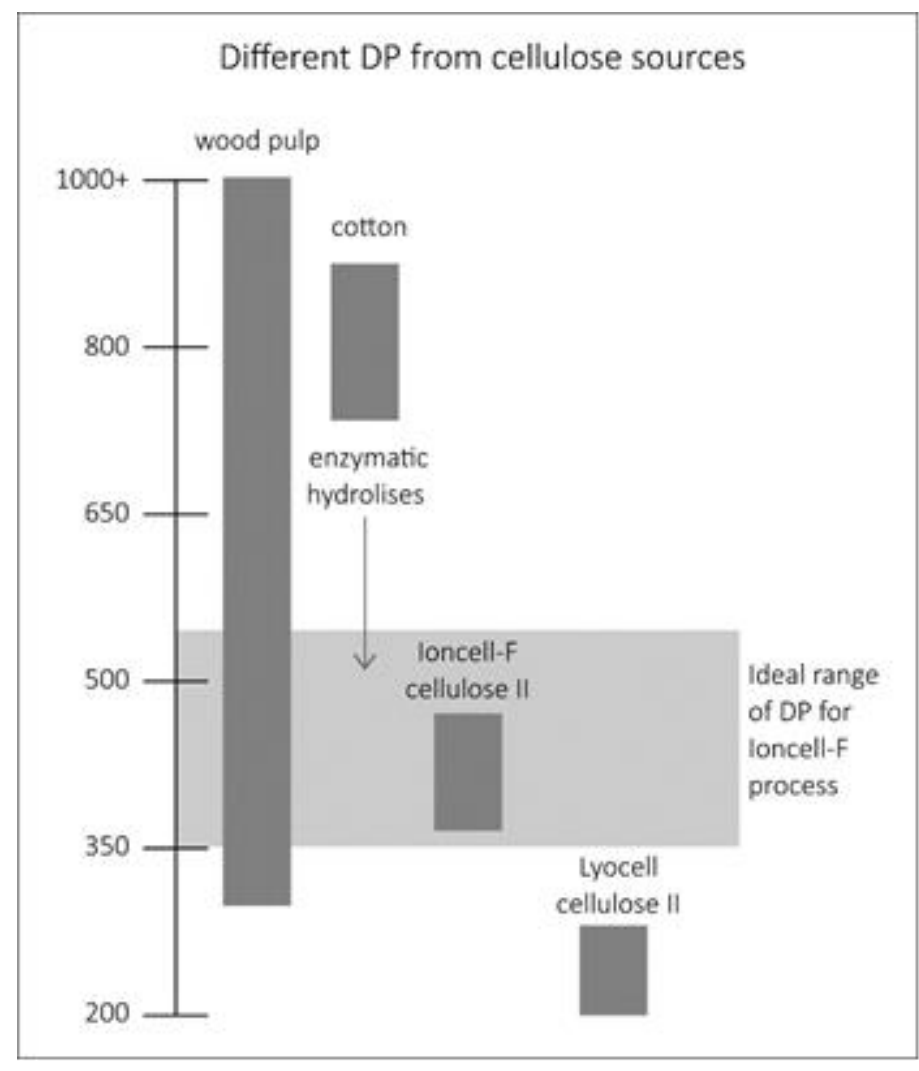

Graphic 1: Example of different DP from different cellulose sources and the comparison with the proper range for regeneration process (Ioncell-F). Source: Author's elaboration 


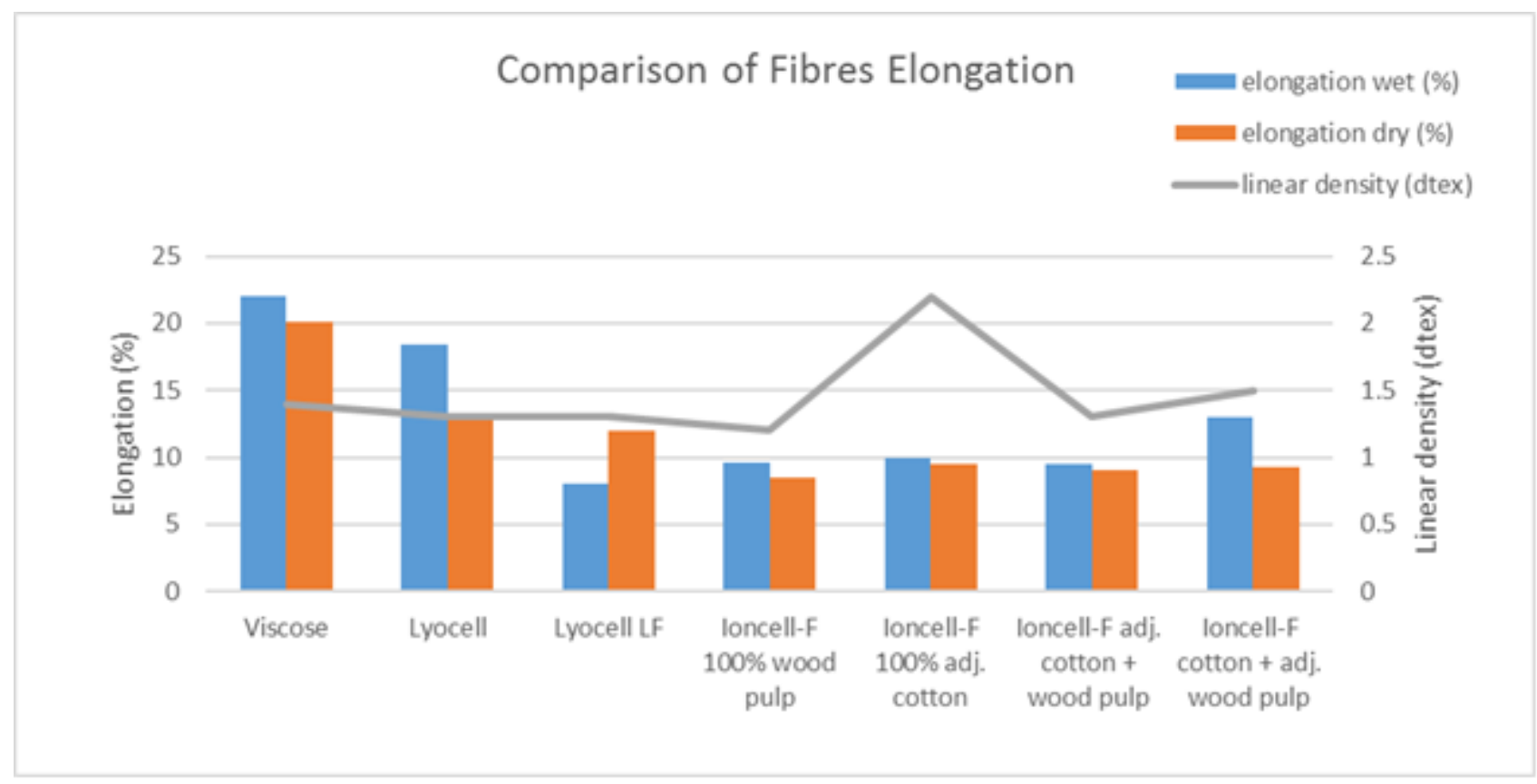

Graphic 2: Elongation comparison between commercial regenerated fibres and Ioncell-F tested with different inputs. Source: Author's elaboration from Ioncell-F and Lyocell LF informational reports

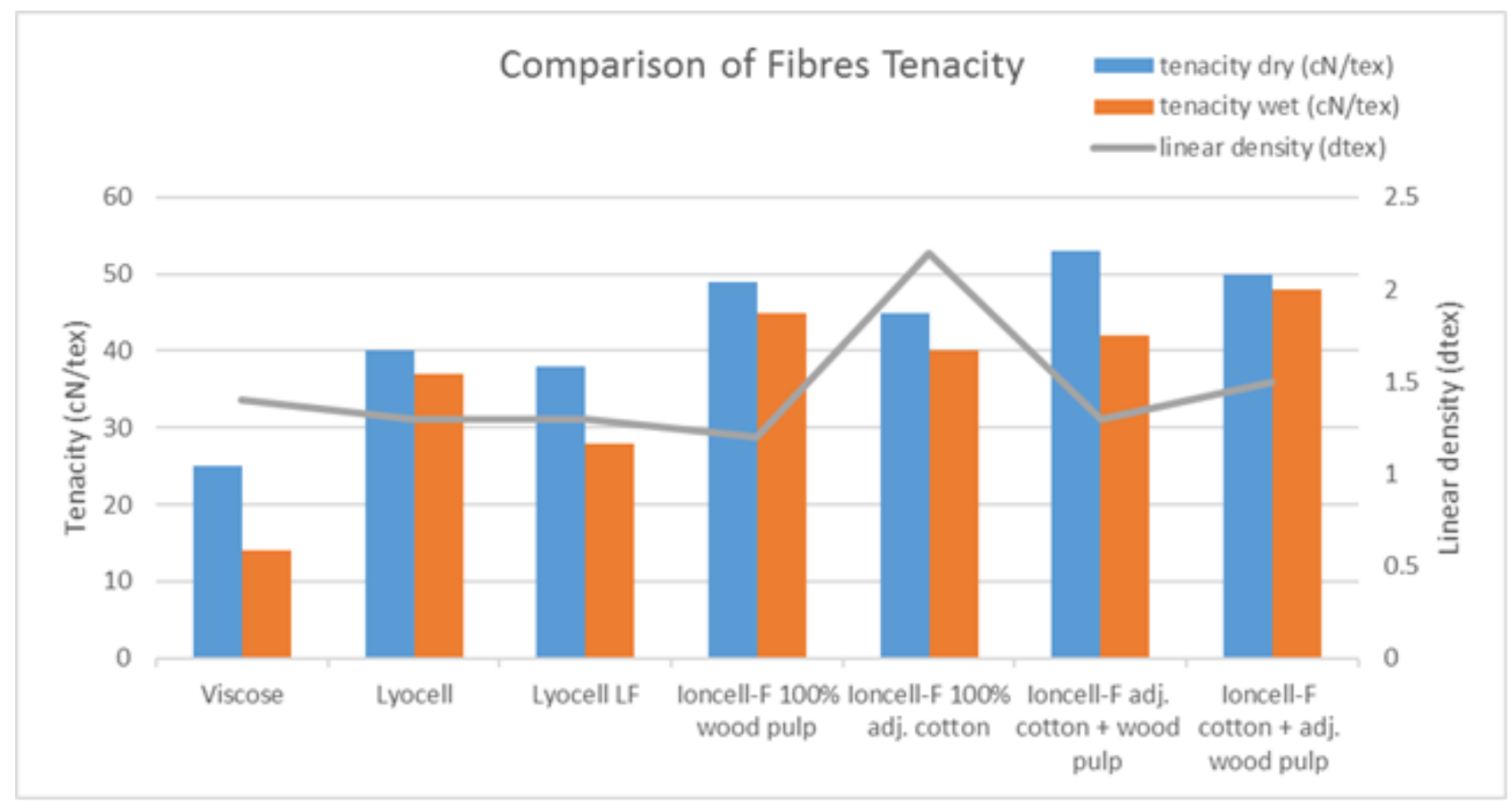

Graphic 3: Tenacity comparison between commercial regenerated fibres and Ioncell-F tested with different inputs. Source: Author's elaboration from Ioncell-F and Lyocell LF informational reports 


\subsection{Challenges on the chemical recycle of cotton implementation}

When talking about textile end-of-life, basically the options are to discard, to sell, or to donate to charity organizations, municipalities, retail collectors or professional collectors (Zamani, 2014). It is important to mention, the export of textiles, which represents $84 \%$ of all collected textiles in Europa, should be reconsidered (Smits, 2015). Currently, most of the textiles which retain high enough quality for reuse are sent to East European or African countries (Palme et al., 2014). In 2008, only in Sweden, 26000 tonnes of collected used clothes and shoes were donated to Africa and Eastern Europe (Zamani, 2014). The advantages of increasing the waste stream designated to recycle - despite the huge business margin for improvements - is related to its low human toxicity, terrestrial ecotoxicity, reduce of need on raw material and water consumption among others. Anyways, the chemical recycle, as mechanical recycle, represents challenges on its structure.

\subsubsection{Recovering and sort the proper input}

Recovering and sort the required textiles would be first steps to be faced. As example: at one German SOEX plant - an international textile collecting company - 400 tons of textiles are received every day (X:enius, 2015). These textiles are mainly separated by hand, initially in three categories: jeans without stretch, other wearable garments (up to 50\%), and non-wearable garments. Jeans are designated for fibre recycle; wearable garments proceed to second-hand sales, and nonwearables are shredded. Even if upcycling is possible right now for mono-material garments for example, sort companies are not able to recognize or to know it due to communication/identification problems. Few supporting technologies are available as QR or RFID codes, but they are considered still unaffordable and time consuming due to manual scan (Zwart, 2015).

Nevertheless, an invention from 2014 might be a big step toward betterment. Valvan Company developed "Fibersort", a machine that recognize the composition of textiles through infra-red scan in a speed of 1 piece per second with accuracy of $98 \%$ (Smits, 2015). It is a first step toward an automatized solution, and even if there is no limit to the types of fibre that can be recognized, there are still few technical issues to be improved (Zwart, 2015). The system scans $1 \mathrm{~cm}^{2}$ of each garment, so it cannot identify different composition in different parts of a same piece; it works with light reflection thus it is hard to identify black clothes; the thickness of the garment interferes in the identification, because it can get too close to the light point. Conversely, only ten different compositions comprise $80 \%$ of the sort, from those $70 \%$ are pure (with $45 \%$ to $55 \%$ consisting in cotton) and the other $30 \%$ are blends (being PES/CO the majority) (Smits, 2015). This way sort is relevant, as the scalable chemical recycling technologies will require appropriate feedstock in the medium term, once market demand increases.

Considerations must be taken as well in the environmental and social issues related to the raw material. Even with advanced scanning technology, the toxicity levels, for instance, are not detectable. In the optimal situations, non-toxic recovered materials should not be contaminated with other conventional non sustainable textiles. And as the market walks toward a shift, from conventional, to certified, and finally to beneficial Cradle to Cradle ${ }^{\circledR}$, so the recovery and sort should also develop.

Finally, another issue to be analysed is the hardware as fasteners and buttons, because it requires manual work in disassemble and it is considered a bottleneck in the recycle way. New and disruptive innovations in design strategies may be needed in order to facilitate the future recycle. 


\title{
3.3.2 Colours and other impurities
}

Colours represent a big issue to the continuity of the chemical recycle, what is very different from reuse. When thinking about reuse, many possibilities are available. For the decolouring, for instance, could be mentioned prior bleaching, ${ }^{1}$ but it is actually breaking down the colour molecule, which cannot refract the light anymore, giving so the impression of "no colour". But the molecules, even if not visible, are still there. The same happens with prints and other components as synthetic blends. It does not interfere the mechanical recycle, and in a small level, it may not interfere in the first spinning process of chemical recycle as well, but it would create certain impurity to the fibre or to the solvent. These impurities would be cumulative and could make the continuous recycle process impossible. Coloured filaments or a coloured coagulation bath may occur in the case of coloured material is dissolved and spun again. In any case, this colour would still interfere in future processes - in case of re-regenerating these fibres or recovering the coagulation bath. More research is still necessary in this field, and efforts must be placed on the beginning of the processes to avoid future undesirable discoveries (Ioncell-F, 2015a).

In the polyester industry, for instance, it is already possible to dye and now remove dyes from fabric with $\mathrm{CO} 2$, and these dyes could be also recycled (Feye Con, s.d.). There is also a plasma technology developed to remove all added finishing and coatings from a textile such as water repellents (Ecotextile, 2014). In a foreseen future, these technologies may be also suitable to cellulose-based textiles.

\subsubsection{Market parameters}

For Alan Wheeler, director at Textile Recycling Association in UK,

\begin{abstract}
"the lack of markets and the low value of recycling grades are significant barriers, presenting a "chicken and egg" situation. How does one create or stimulate new markets for fibre recycling when there is a lack of collections designed for recycle and which can supply the correct fibre with suitably low contamination levels? And on the other side, how to persuade a collector to target recycling grades without the market? In this situation, to sort at an affordable price is a key issue as are blends. New technologies may go some way to overcoming these problems, but a shirt that purports to be $100 \%$ of one fibre (e.g. polyester) may still have plastic buttons, metal zips, cotton thread, all of these are contaminants that need to be removed by recycling can take place. Consideration on Design for Recycling and Design for Disassembly protocols may help." (Wheeler, 2015)
\end{abstract}

Fact is that the textile industry should unify efforts towards better results. The Circular Textile Program from Circle Economy, launched in September 2014, is one example. The French organisation Eco TLC invests in a number of R\&D projects to develop new markets for recycling. WRAP undertakes extensive work to help improve overall sustainability of the UK clothing supply chain. The trash-2-cash project, launched in June 2015, unifies almost 20 institutions and companies all over Europe to increase recycle through design-driven innovation. Trash-2-cash is a program supported by Horizon 2020, the biggest EU Research and Innovation programme ever with nearly $€ 80$ billion of funding available over 7 years - 2014 to 2020 (T2C, 2015). In Germany, a new

\footnotetext{
${ }^{1}$ Chloride bleaching alternatives must be considered, as hydrogen peroxide, ozone, enzyme technologies (not allowed in GOTS due to GMO background) (Fletcher \& Grose, 2012, pg.34), or even $\mathrm{CO}_{2}$ (Feye Con, s.d.).
} 
steering committee for the German Partnership for Sustainable Textiles met together for the first time August 2015, including representatives from the textile industry and fashion retailers. The Textile Partnership, created by International Development Minister Gerd Müller, aims to develop and set collective standards for global sustainable production in the textile sector (Made-By, 2015). Unquestionably, without coalition, implementing new processes would be barely possible.

Regarding to the technology, chemical recycling of cotton textiles is shown to be possible when considering the proper sort, the appropriate colour input and the purity composition. But the volatile price and its continuing decline on the global viscose fibre market since 2013, could be still an obstacle to its introduction. For Lenzing, for example, the generally lower fibre selling prices in 2013 also led to moderate price adjustments for TenCel®. Whereas average fibre selling prices in the first quarter of 2013 equalled $€ 1.77$ per kilogram (in comparison to first quarter of 2012: $€ 2.03$ ), they continually decreased to a level of $€ 1.61$ per kilogram in the fourth quarter of the year (in comparison to fourth quarter of 2012: €1.83) (Lenzing, 2013). Additionally, as the commercialization of ILs is quite recent, their costs are still higher than the commercial solvents already available. It could be balanced through the growth of the demand (as happened in the process of commercialization of NMMO), and the fully recovery of the solvent. Although the recovery by distillation is possible, further researches are considering its energy optimization.

\subsubsection{Blends}

Moreover, the chemical recycle of cellulose textiles is still upscaling, and although it represents a very important step forward, it is by no means a perfect solution. The regeneration of cellulose materials is just a part of the larger evolution in the recycling structure. As many of the textiles produced are presented in blends, commonly polyester and cotton, it is important to think about new technologies that could allow the use of blends accordingly.

Worn Again, in partnership with Kering and H\&M, has announced in April 2015 the plan of working on chemical recycle of blended materials, mentioning that "there are currently no available textile-to-textile recycling processes for polyester/cotton blends, so many of these resources are currently perceived as a downcycling stream, with little or no economic value". In the process, the recaptured polyester will then be turned into polyester pellets of the same quality, functionality and price as those made from virgin oil by-products. Also, re-capture cellulose from cotton and mixed fibre garments will be introduced as feedstock into existing cellulosic fibre production and/or by the creation of a new cellulosic fibre, leaving behind dyes and other contaminants.

\section{CONCLUSION}

The humanity is using more natural resources than can be sustained from Earth in the long term. Already back in 2001, the global textile consumption overlapped the planet's maximal point of supply (SEI, 2005, pg.30). Besides that, the forecast of the decrease of resources, the growth of the population, the increase in demand for textiles, water and arable land makes the case for an urgent shift in the way fashion is produced and consumed. Fortunately, the world started to move toward betterment, and initiatives supporting social and environmental standards have been more disseminated.

This article presents an innovative environmental alternative related to the extension of lifecycle of cellulosic textiles through the medium of chemical recycling. Its core values are: the reduction of landfill, water consumption, and the direct dependence on arable land. Further, this regenerated fibre could fulfil the previewed gab in cotton supply, using low quality material as input and offering high quality fibres as output. As with all new technology or process, it faces 
challenges and obstacles. The market price in general, and the high price of the solvent used due to low demand are still barriers.

Recycling companies and systems should support such practice. Currently, the export of used garments from Europe - primarily for the second hand and downcycled markets - complicates the possibilities for recycling. Stronger investments in the textile-to-textile recycle are required in order to change it. These investments include; the materials available, the design strategy adopted and all haberdasheries, the proper structure to sort and recycle those garments/textiles as to find solution for current issues such as dyes, prints and other finishing. It also includes the increase of customers' awareness, and better governmental policies.

In an optimal scenario, the recycle of old cellulosic textiles, not only cotton, would be applicable, and the life cycle of this natural polymer would be abundantly extended. Ideally, the input would be proper selected as GOTS certified garments and further, with Cradle to Cradle ${ }^{\circledR}$ certified textiles. This definition would not only attack issues on recycling and landfilling, but would also provide the potential opportunity to companies of material ownership in the biological sphere, valuing prior investments on the elimination of all hazardous chemicals.

The chemical recycling of cotton textiles as presented is not yet available in industrial scale although this process has been awarded with 300,000 euros for investments from the H\&M Global Change Award 2015 - and does not function as a total solution to the issue. It is important to unify efforts from all market levels in order to spread this (an others) sustainable process(es). But even if the industrial scale proves to be feasible, market entry may be difficult due to close market with only few large players. Few representative companies in the market share could offer resistance instead of support. In order to truly move forward, it will be necessary to unify the different groups, institutions, developers, researchers, companies, and the government with supportive legislations, to guarantee the successful evolution of a sustainable fashion industry.

\section{AKNOWLEDGEMENTS}

It is a pleasure to thank those who provided assistance in form of content, advices, suggestions, and network, and made this paper possible. I specially thank Shirin Asaadi, PhD researcher on the chemical recycle of cotton textiles, on who I have relied heavily on the support, understanding and expertise. As well as other members from Prof Herbert Sixta's Biorefineries Group - Department of Forest Products Technology, Aalto University, Finland: Dr Michael Hummel, Anne Michud, Yibo Ma, and Majaana Tanttu. I am also heartily thankful to Dr Kirsten Brodde from Greenpeace and to Alan Wheeler, Director of Textiles Recycling Association in the UK, whose sincere and encouraging words enabled me to understand the relevance and the challenges of the subject, and go forward in a more dynamic approach.

\section{REFERENCES}

ASAADI, S.; HUMMEL, M.; SIXTA, H. Ioncell-F presentation: Cellulosic fibres from novel - Ionic liquidrecycled cotton solutions by dry-jet wet spinning. The 6th Workshop on Cellulose, Regenerated Cellulose and Cellulose Derivatives, Karlstad, Sweden, 11th - 12th November 2014.

BURROW, T.R. Recent advances in chemically treated Lyocell fibres. Lenzinger Berichte,84 110-115. Tencel®C Ltd, Derby, UK, 2005.

CAMACHO, L.R. Author's interview with Leandro Rosa Camacho, vice president of the Brazilian Chemical Association - RS state division. 18th February 2015.

ECO TLC - L'éco-organisme du textile, du linge, de la chassure. Roads to Innovation Journal, Jun. 2014. 
ECOTEXTILE. Plasma fabric recovery from Taiwan. At http://www.ecotextile.com/2014022012457/fashion-retailnews/plasma-fabric-recovery-from-taiwan.html. Ecotextile (20 February 2014) [accessed: 30th July 2015 ].

ELLEN MACARTHUR Foundation report. Towards the Circular Economy: Opportunities for the consumer goods sector. V.02. Ellen MacArthur Foundation, 2013.

FEYE CON Company. CO2 Technology. s.d. At http://www.feyecon.com/co2-technology [accessed: 30th August 2015].

FLETCHER, K.; GROSE, L. Fashion and Sustainability: Design for Change. Laurence King Publishing, 2012.

GCA. Global Change Award from H\&M Conscious Foundation (2015). At globalchangeaward.com [accessed: 26th August 2015].

GOTS - Global Organic Textile Standards. GOTS presentation with Herbert Ladwig - excecutive director, Claudia Kersten - marketing director for Germany, Austria and Switzerland, and Sumit Gupta - India representative from Global Organic Textile Standard. Esmod Berlin, Germany. 10th July 2015.

Helsinki Innovation Services. Ioncell - a new textile fibre. At http://www.his.fi/en/articles/ioncell-a-new-textile-fibre [accessed: 14th April 2015].

HORIZON 2020. Horizon 2020 project. At http://ec.europa.eu/programmes/horizon2020/en [accessed: 12th August $2015]$.

HUMMEL, M., et al. Ioncell-F presentation: Ioncell-F - High strength fibres from various ligno-cellulosic materials. At Coffee and Science at Aalto University, Espoo, Finland. 22nd May 2015.

IONCELL-F (a), Aalto University visit. Author's interview with Prof Herbert Sixta's Biorefineries Group: Dr Michael Hummel - spinning leader, Shirin Asaadi - PhD researcher in chemical recycle of cotton, Anne Michud - PhD researcher in Ioncell-F process optimization, Yibo $\mathrm{Ma}-\mathrm{PhD}$ researcher in chemical recycle of paper/lignin contents, Marjaana Tanttu - textile designer. At the Department of Forest Products Technology, School of Chemical Technology at Aalto University, Espoo, Finland. 21st - 22nd May 2015.

IONCELL-F (b). Ioncell-F - Cellulosic Fibers from Ionic Liquid Solution - Aalto University Research Available at https://www.youtube.com/watch?v=5bhCbGmNfTQ [accessed: 15th April 2015].

KERING. H\&M, Kering and innovation company Worn Again join forces. At http://www.kering.com/sites/default/files/press_release/wa_kering_hm_pressrelease_31032015_eng.pdf [accessed: 3rd April 2015].

LAURI K., et al. Dry jet-wet spinning of strong cellulose filaments from ionic liquid solution. Springer Science + Business Media Dordrecht, 2014.

LENZING report. The Sources of our Strength. Annual Report- Lenzing Group. Austria, 2013.

LENZING. Tencel Specifications. s.d. At http://www.lenzing.com/en/fibers/tencel/specifications.html [accessed: 30th March 2015].

MA, Y., et al. Upcycling of waste paper and cardboard to textiles. Green Chemistry Magazine. Issue 3. DOI: 10.1039/C5GC01679G. 2016.

MADE-BY Top News. First steering committee meeting for Germany's Textile Partnership. At http://www.madeby.org/news/top/ [accessed: 25th August 2015].

MCDONOUGH, W.; BRAUNGART, M. Cradle to Cradle: Remaking the Way We Make Things. New York: North Point Press, 2002.

MCKINSEY \& Company report. Resource Revolution: Meeting the world's energy, materials, food, and water need. 2011.

MICHUD, A., et al. Ioncell-F: ionic liquid-based cellulosic textile fibres as an alternative to viscose and Lyocell. Textile Research Journal, 2015.

NEBEL, K. Author's interview with Kai Nebel, head of textile engineering and product development, and research coordinator at Fakultät Textil und Design, Hochschule Reutlingen, Germany. 2nd May 2015.

OLSSON, C. Cellulose Processing in Ionic Liquid Based Solvents. Gothenburg: Chalmers University of Technology. 2014. 
OUTI LES PYY. Ioncell ya Marimekko (Ioncell and Marimekko) (2014). At http://outilespyy.com/ioncell-jamarimekko/\# [accessed: 10th March 2015].

PALME, A., et al. Chemical and ultrastructural changes in cotton cellulose induced by laundering and textile use. DOI 10.1007/s10570-014-0434-9. 2014.

PATAgOnia. Closing the Loop - A Report on Patagonia's Common Threads Garment Recycling Program (2009). At http://www.thecleanestline.com/2009/03/closing-the-loop-a-report-on-patagonias-common-threads-garmentrecycling-program.html [accessed: 12th March 2015].

ROHRER, C., et al. Lyocell LF - Profile of a fibrillation-free fibre from Lenzing. Lenzing Group, Austria, 2001.

SEI Stockholm Environment Institute report. Ecological Footprint and Water Analysis of Cotton, Hemp and Polyester. Stockholm, Sweden, 2005.

SIXTA, H., et al. Ioncell-F: A High-strength regenerated cellulose fibre. Nordic Pulp \& Paper research Journal, 30 Jan. 2015: 43-57.

SMITS, H. Circle Economy presentation: Circular Textile Program. Circular Textile Challenges at Open Source Circular Economy Days, Berlin, Germany, June 2015.

SWATLOSKI, R.P., et al. Dissolution of Cellulose with Ionic Liquids - Abstract. Centre for Green Manufacturing and Department of Chemistry, University of Alabama. American Chemical Society. DOI: 10.1021/ja025790m. 2002.

T2C. Trash-2-Cash Program. At http://trash2cashproject.eu/ [accessed: 1st June 2015]

Valvan Baling Systems nv. The Fibersort. Available at https://www.youtube.com/watch?v=Ye9Q-jzSEuQ [accessed:October 2014].

WESTIN, M. SP presentation: Från CelluNova till Trash-2-Cash. SP Technical Research Institute of Sweden - SP day: The forest in the catwalk, Textile Fashion Centre, University of Borås, Sweden. 27th April 2015.

WHEELER, A. Author's interview with Alan Wheeler, director at Textile Recycling Association in UK. 27th May 2015.

WRAP report. Evaluating the financial viability and resources applications for new business models in the clothing sector. Waste \& Resource Action Programme, UK. 2013.

WRAP report. Valuating our clothes - The true costs of how we design, use and dispose clothing in the UK. Waste \& Resource Action Programme, UK. 2012.

X:ENIUS Documentary. Kleider Recycling (Clothes Recycling). At https://www.youtube.com/watch?v=n61x7V65Q8 [accessed: 30th January 2015].

ZAMANI, B. Towards Understanding Sustainable Textile Waste Management - Environmental impacts and social indicators. Gothenburg: Chalmers University of Technology. ISSN: 1652-943X. 2014.

ZWART, T. Author's interview with Tamara Zwart, Head of Closed Loop Alliance at I:CO, 17th January 2015. 